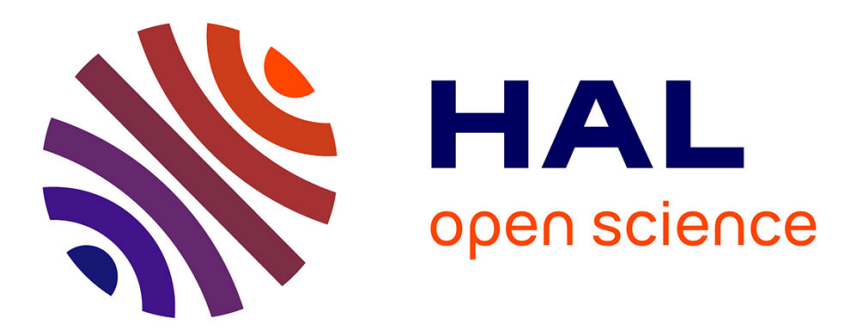

\title{
Air pollution and humidity as triggering factors for stroke. Results of a 12-year analysis in the West Paris area
}

\author{
C. Hirel, L. Berton, C. Preda, O. Richard, Y. Lambert, F. Pico
}

\section{To cite this version:}

C. Hirel, L. Berton, C. Preda, O. Richard, Y. Lambert, et al.. Air pollution and humidity as triggering factors for stroke. Results of a 12-year analysis in the West Paris area. Revue Neurologique, 2019, 175, pp.614 - 618. 10.1016/j.neurol.2019.03.002 . hal-03488517

\section{HAL Id: hal-03488517 \\ https://hal.science/hal-03488517}

Submitted on 21 Dec 2021

HAL is a multi-disciplinary open access archive for the deposit and dissemination of scientific research documents, whether they are published or not. The documents may come from teaching and research institutions in France or abroad, or from public or private research centers.
L'archive ouverte pluridisciplinaire HAL, est destinée au dépôt et à la diffusion de documents scientifiques de niveau recherche, publiés ou non, émanant des établissements d'enseignement et de recherche français ou étrangers, des laboratoires publics ou privés.

\section{(c) (1) $\$$}

Distributed under a Creative Commons Attribution - NonCommerciall 4.0 International 


\section{Air Pollution and Humidity as Triggering Factors for Stroke. Results of a 12-year Analysis in the West Paris Area}

Catherine Hirel ${ }^{1}$, Laurence Berton ${ }^{2}$, Cristian Preda ${ }^{3}$, Olivier Richard ${ }^{2}$, Yves Lambert ${ }^{2}$, Fernando Pico ${ }^{1,4,5 *}$

${ }^{1}$ Neurology Department and Stroke Center, Versailles Hospital Center, Versailles, France; ${ }^{2}$ SAMU 78 (L.B., O.R., Y.L.), Versailles Hospital Center, Versailles, France; ${ }^{3}$ Mathematical laboratory, Paul Painlévé, UMR CNRS 8524, University of Science and Technology, Lille, France

${ }^{4}$ Université Versailles Saint-Quentin en Yvelines et Paris Saclay, France ${ }^{5}$ INSERM LVTS (Laboratory for Vascular Translational Science)-1148,Paris, France

*Correspondence to Fernando Pico, MD, PhD. Department of Neurology and Stroke Center, Centre Hospitalier de Versailles: 177 Rue de Versailles, 78150 Le Chesnay France. E-mail: FPico@ch-versailles.fr, Tel: 0033139639147.

Fax: 0033139639738

Cover Title: Air Pollution and Humidity as Triggers for Stroke 


\section{Abstract}

Background and Purpose-Previous studies have suggested an association between stroke and meteorological factors, air pollution and acute respiratory infections as triggering factors. Often, these factors have been evaluated separately. We evaluated the association between all these environmental triggering factors and calls for suspected stroke in a suburb in west Paris from 2004 to 2015.

Methods - We used data from the emergency medical dispatching center of all calls for suspected stroke (SAMU 78), climatic parameters (MétéoFrance), pollution (AIRPARIF), and data from influenza epidemic surveillance networks (GROG and Sentinelles). The association between short-term exposure (1-day lag) to environmental triggering factors and stroke occurrence was analyzed using negative-binomial log linear regression model for counting time series.

Results - Between 2004 and 2015, a total of 11037 calls for suspected stroke were recorded. In bivariate analysis, there were associations between calls for suspected stroke and temperature (mean, maximum and minimum), humidity and influenza epidemic. In multivariable analysis, only two variables were associated with calls for suspected stroke: humidity $(3.93 \%$ excess relative risk [ERR] of stroke per $10 \%$ increase in humidity; $95 \%$ confidence interval $[\mathrm{CI}], 1.42$ to $6.51 ; \mathrm{p}<0.002)$ and pollution on the "Air Parif Atmo" scale (2.86\% ERR of stroke per 1 unit increase; $95 \% \mathrm{CI}, 1.01$ to $4.75 ; \mathrm{p}=0.002)$.

Conclusions - This study suggests that short-term exposure to air pollution and a high level of humidity are associated with a significant excess relative risk of calls for suspected stroke.

Key Words: stroke, humidity, pollution, influenza, climate 


\section{Introduction}

Cardiovascular diseases are the leading cause of disability in industrialized countries despite treatments to reduce cardiovascular risk factors [1]. Correlations between stroke and extreme temperatures and atmospheric pollution (especially ozone) have been shown in various studies [2-6]. In Paris, a link between extreme temperatures, influenza epidemic and myocardial infarction has been shown [7]. Recently, a consistent association was found between laboratory-confirmed influenza infection and acute myocardial infarction [8].

The goal of our 12-year study was to analyze the relationship between the numbers of calls for suspected stroke to the emergency medical dispatching center and suspected triggering factors: meteorological data, atmospheric pollution and influenza epidemics.

\section{Materials and Methods}

\subsection{Data Collection}

The emergency medical dispatching center of a western suburb of Paris - "Service d'Aide Médicale Urgente" (SAMU 78) collected daily data of calls for suspected stroke. The suburb of Paris is the Yvelines department and it has 1.4 million inhabitants. For the stroke data, 75\% were collected from firefighter or ambulance balance sheets and 25\% from emergency mobile services. All data were collected on ACCESS ${ }^{\circledR}$. In this study, we used data collected from January 1, 2004 to December 31, 2015. In order to assess the validity of the code used in the register, C.H. verified all the medical reports of 268 patients with suspected stroke who were brought to our stroke center during 1 year. Diagnosis at discharge was: 130 cerebral infarctions, 20 transient ischemic attacks, 39 cerebral hemorrhages and 79 other diagnoses (six comas, 12 confusions, 18 epileptic attacks and 43 other diagnoses). Therefore, $70.5 \%$ of suspected stroke episodes were diagnosed as stroke, so the accuracy of a suspected stroke call as a surrogate for a diagnosis of stroke is $70.5 \%$. 
Meteorological data were extracted from the "MétéoFrance" (French national institute of meteorology) databases: temperature (mean, minimum, maximum and range); wind speed (mean and maximum); mean atmospheric pressure; and mean humidity.

Atmospheric pollution data were obtained from the "AIRPARIF" databases. The analyzed pollutants are carbon monoxide, nitrogen dioxide, sulfur dioxide, ozone and fine particles. We chose to use the global index of pollution. The "AirParif Atmo" index (1 to 10) has been used since 2004, so was used in this study. The "Citéair" index has only been used since 2011, so was not used in the present study in order to ensure comparability over the entire study period.

Influenza data were collected from the "GROG" network (regional groups for influenza surveillance) and the "Sentinelles" network (réseau Sentinelles, INSERM/UPMC, http://www.sentiweb.fr). We recovered national data regarding influenza epidemics from 2004 to 2015 (weeks of the year above the epidemic threshold, influenza strain involved) and regional data (number of cases per week).

\subsection{Statistical Analysis}

Data are presented as time series of counts of the numbers of calls for suspected stroke and as time series of values of environmental and pollution parameters. Descriptive univariate and bivariate statistics are presented for all parameters. For numerical time series, Spearman correlations are presented, whereas the associations between a categorical time series (presence of influenza) and a numeric valued one was measured using Wilcoxon statistics.

To assess the associations between the numbers of calls for suspected stroke and the environmental and pollution parameters, we fitted negative-binomial log-linear regression models for count time series. Based on the probability integral transform histogram, that models fitted better than using Poisson modeling. Univariate models were fitted for each 
predictor with a 1-day lag. The correlation between the parameters was accounted for in a multivariable model that included all of the predictors at a 1-day lag. Excess relative risk (ERR) was computed for each parameter in the bivariate and multivariable models. We adjusted for potential confounders in the multivariable model, e.g. weekends. All statistical analyses were performed with the $\mathrm{R}$ software and the tscount $\mathrm{R}$ package was used to fit the generalized linear regression models for count time-series [9].

In accordance with the French legislation, this study did not need approval by an ethics committee or written informed consent from patients because it only encompassed the analysis of anonymized data that had been collected prospectively as part of routine clinical care.

\section{Results}

\subsection{Number of Calls for Suspected Stroke}

A total of 11037 calls for suspected stroke were recorded during the 4383 days of the study (January 1, 2004 to December 31, 2015). The number of calls for suspected stroke increased from 748 in 2004 to 1081 in 2015 (Figure 1), a much larger increase than the population increase in our area from 1.38 million in 2004 to 1.42 million in 2015 . The median daily number of calls for suspected stroke was two during the whole study period (Table 1).

\subsection{Triggering Factors for Stroke and their Correlations}

Table 1 contains the descriptive values of the main climatic parameters and pollution during the whole study period. Table 2 presents the Spearman correlations between these factors. There were significant negative correlations between humidity and temperature; humidity and atmospheric pollution; and wind speed and atmospheric pollution. There was a significant positive correlation between temperature and atmospheric pollution. 
During the study period, there was an influenza epidemic each year. Overall, there were 746 days of influenza epidemic out of 4383 days (17.0\%). During influenza epidemic days versus non-influenza epidemic days, the temperature was lower $(P<0.001)$, humidity was higher $(P<0.001)$, mean atmospheric pressure was higher $(P=0.047)$, and mean wind speed was higher $(P<0.001)$, but pollution was similar $(P=0.317)$.

\subsection{Relationships Between Triggering Factors and Calls for Suspected Stroke}

Table 3 presents the results of bivariate analysis between potential triggering factors and calls for suspected stroke. There were significantly increased risks of suspected stroke calls with $10^{\circ} \mathrm{C}$ decreases in mean, minimum or maximum temperatures (all $P<0.001$; Table 3 ), a $10 \%$ increase in humidity $(P<0.001)$ and during influenza epidemics $(P=0.0012)$. There were not significant relationships between numbers of calls for suspected stroke and atmospheric pressure, wind speed or atmospheric pollution.

In multivariable analysis, two factors were significantly associated with the number of calls for suspected stroke: a 10\% increase in humidity (ERR 3.93\%, 95\% confidence interval [CI] 1.42 to $6.51, P<0.002)$ and a one-point increase in the Air Parif Atmo index (ERR 2.86\%, 95\% CI 1.01 to $4.75, P=0.002$ ) (Table 4).

\section{Discussion}

We observed in the study an important increase of calls for suspected stroke from 2004 to 2015. This increase has several explanations: the authorization of rt-PA in 2003, the "PLAN AVC" in 2010 and the ageing and growth of the population, who led to a rise in the absolute number of strokes [10]. 
This study suggests associations between stroke and humidity and atmospheric pollution in multivariable analysis. In bivariate analysis, we observed associations between stroke and temperature, humidity and influenza epidemics. The association between stroke and temperature disappeared in multivariable analysis because of the negative correlation between temperature and humidity. In multivariable analysis, by adjusting on climatic parameters, there was no correlation between stroke and influenza epidemics.

An association between atmospheric pollution and stroke mortality in England and Wales was reported in 1981 [11]. A subsequent analysis of 19000 strokes that occurred between 1991 and 1997 in Seoul reported a significant excess risk of mortality for brain infarctions during exposure to atmospheric pollution [12]. Similar results have since been reported in another study from England [3], suggesting that air pollution is a deleterious factor for stroke and stroke mortality. Similarly to our multivariable results, other studies have also shown that air pollution can be a triggering factor for stroke occurrence [3,6,13-16].

Associations between humidity and stroke have also been previously observed [5,17]. A 3-year retrospective study in Sarajevo reported that extreme levels of humidity were significantly associated with the incidence of stroke [17]. Another study - in Boston - showed an association between stroke and cooler temperatures, especially on days with higher levels of relative humidity [5].

In our study, we did not find a link between suspected stroke and influenza epidemic after adjustment for climatic and pollution factors. However, a French case-control study reported that vaccination against influenza reduced the risk of stroke [18]. Moreover, two studies have reported links between myocardial infarction and either influenza epidemics [7] or positive test results for influenza [8]. We can formulate two hypotheses. The first hypothesis is that influenza epidemic is a triggering factor for stroke occurrence, but our study was underpowered to detect it. Moreover, we can hypothesize that influenza infection only triggers 
atherothrombotic stroke. In favor of this hypothesis is a study that reported an association between influenza and myocardial infarction, but not between influenza and stroke [19]. The second hypothesis is that influenza infection is not a triggering factor for stroke occurrence, rather, that influenza epidemic is a marker of a specific climate pattern (low temperature and high humidity). Of note, in the above-mentioned studies, climatic patterns and pollution were not accounted for in the multivariable analyses.

\subsection{Strengths and Limitations}

The strengths of our study are the robust data collection from the SAMU; the fact that we took potential cofounders (i.e. climate, pollution, epidemic influenza) into account; and that the statistical analysis was adapted to the nature of the data (negative-binomial log linear regression model for counting time series and table of correlation).

The main limitation of our study is that we used calls for suspected stroke as a surrogate marker for stroke. To ascertain how accurate this marker was, we performed an ancillary analysis that demonstrated that $70.5 \%$ of suspected stroke calls resulted in a diagnosis of stroke. This indicates that our results are likely a reasonable representation of the effect of climate and pollution on stroke. Regarding the results of influenza epidemic, maybe influenza infection, asserted by biological tests, would be likely more relevant to study.

\section{Conclusions}

Our findings, in combination with previous evidence, indicate that various climatic and infectious factors could be involved in the occurrence of stroke. Future studies are therefore warranted to evaluate the potential role of pollution and climate as triggering factors for stroke to evaluate the impact of stroke awareness directed at high-risk patients, particularly during times of high-risk weather and/or pollution. 


\section{Acknowledgments}

We thank Denis Fourgassie for the data from Météo France. We thank Jenny Lloyd (MedLink Healthcare Communications) for editorial assistance for English editing and the Centre Hospitalier de Versailles for funding editorial assistance.

\section{Sources of Funding}

Centre Hospitalier de Versailles for funding editorial assistance.

\section{Disclosures}

None 


\section{References}

[1] Mendis S, Puska P, Norrving B, World Health Organization, World Heart Federation, World Stroke Organization, editors. Global atlas on cardiovascular disease prevention and control. Geneva: World Health Organization in collaboration with the World Heart Federation and the World Stroke Organization; 2011.

[2] Henrotin JB, Besancenot JP, Bejot Y, Giroud M. Short-term effects of ozone air pollution on ischaemic stroke occurrence: a case-crossover analysis from a 10-year populationbased study in Dijon, France. Occup Environ Med 2007;64:439-45. doi:10.1136/oem.2006.029306.

[3] Maheswaran R, Haining RP, Brindley P, Law J, Pearson T, Fryers PR, et al. Outdoor air pollution and stroke in Sheffield, United Kingdom: a small-area level geographical study. Stroke J Cereb Circ 2005;36:239-43. doi:10.1161/01.STR.0000151363.71221.12.

[4] Matsumoto M, Ishikawa S, Kajii E. Cumulative effects of weather on stroke incidence: a multi-community cohort study in Japan. J Epidemiol Jpn Epidemiol Assoc 2010;20:13642.

[5] Mostofsky E, Wilker EH, Schwartz J, Zanobetti A, Gold DR, Wellenius GA, et al. Shortterm changes in ambient temperature and risk of ischemic stroke. Cerebrovasc Dis Extra 2014;4:9-18. doi:10.1159/000357352.

[6] Suissa L, Fortier M, Lachaud S, Staccini P, Mahagne M-H. Ozone air pollution and ischaemic stroke occurrence: a case-crossover study in Nice, France. BMJ Open 2013;3:e004060. doi:10.1136/bmjopen-2013-004060.

[7] Caussin C, Escolano S, Mustafic H, Bataille S, Tafflet M, Chatignoux E, et al. Short-term exposure to environmental parameters and onset of ST elevation myocardial infarction. The CARDIO-ARSIF registry. Int J Cardiol 2015;183:17-23. doi:10.1016/j.ijcard.2015.01.078.

[8] Kwong JC, Schwartz KL, Campitelli MA, Chung H, Crowcroft NS, Karnauchow T, et al. Acute Myocardial Infarction after Laboratory-Confirmed Influenza Infection. N Engl J Med 2018;378:345-53. doi:10.1056/NEJMoa1702090.

[9] Liboschik T, Fokianos K, Fried R. tscount : An $R$ Package for Analysis of Count Time Series Following Generalized Linear Models. J Stat Softw 2017;82. doi:10.18637/jss.v082.i05.

[10] Béjot Y, Bailly H, Graber M, Garnier L, Laville A, Dubourget L, et al. Impact of the Ageing Population on the Burden of Stroke: The Dijon Stroke Registry. Neuroepidemiology 2019;52:78-85. doi:10.1159/000492820.

[11] Knox EG. Meteorological associations of cerebrovascular disease mortality in England and Wales. J Epidemiol Community Health 1981;35:220-3.

[12] Hong Y-C, Lee J-T, Kim H, Kwon H-J. Air pollution: a new risk factor in ischemic stroke mortality. Stroke J Cereb Circ 2002;33:2165-9.

[13] Lisabeth LD, Escobar JD, Dvonch JT, Sánchez BN, Majersik JJ, Brown DL, et al. Ambient air pollution and risk for ischemic stroke and transient ischemic attack. Ann Neurol 2008;64:53-9. doi:10.1002/ana.21403.

[14] Maheswaran R, Pearson T, Beevers SD, Campbell MJ, Wolfe CD. Outdoor air pollution, subtypes and severity of ischemic stroke--a small-area level ecological study. Int J Health Geogr 2014;13:23. doi:10.1186/1476-072X-13-23.

[15] Tsai S-S, Goggins WB, Chiu H-F, Yang C-Y. Evidence for an association between air pollution and daily stroke admissions in Kaohsiung, Taiwan. Stroke J Cereb Circ 2003;34:2612-6. doi:10.1161/01.STR.0000095564.33543.64. 
[16] Wellenius GA, Schwartz J, Mittleman MA. Air pollution and hospital admissions for ischemic and hemorrhagic stroke among medicare beneficiaries. Stroke J Cereb Circ 2005;36:2549-53. doi:10.1161/01.STR.0000189687.78760.47.

[17] Slatina E, Music M, Babic N, Dervisevic A, Mujaric E, Salibasic M, et al. Correlation between change in air humidity and the incidence of stroke. Mater Socio-Medica 2013;25:242-5. doi:10.5455/msm.2013.25.242-245.

[18] Lavallée P, Perchaud V, Gautier-Bertrand M, Grabli D, Amarenco P. Association between influenza vaccination and reduced risk of brain infarction. Stroke 2002;33:513-8.

[19] Foster ED, Cavanaugh JE, Haynes WG, Yang M, Gerke AK, Tang F, et al. Acute myocardial infarctions, strokes and influenza: seasonal and pandemic effects. Epidemiol Infect 2013;141:735-44. doi:10.1017/S0950268812002890. 


\section{Figure Legend}

Figure 1. Numbers of calls to SAMU78 for suspected stroke each year 
Table 1. Descriptive Statistics for Stroke, Meteorological Data and Pollution Parameters

\begin{tabular}{|c|c|c|c|c|}
\hline Variable & $\begin{array}{l}\text { Missing } \\
\text { data }\end{array}$ & Mean & Median (Q1, Q3) & Range \\
\hline Number of calls for stroke, /day & 0 & 2.51 & $2(1,4)$ & $0-10$ \\
\hline \multicolumn{5}{|l|}{ Temperature, ${ }^{\circ} \mathrm{C}$} \\
\hline Minimum & 29 & 7.55 & $7.8(3.3,12.1)$ & -11.7 to 22.1 \\
\hline Mean & 0 & 11.58 & $11.9(6.8,16.6)$ & -7.4 to 28.7 \\
\hline Maximum & 15 & 15.41 & $15.7(9.6,21.1)$ & -8.8 to 37.5 \\
\hline Range & 39 & 7.86 & $7.5(5,10.5)$ & $0.6-20.3$ \\
\hline \multicolumn{5}{|l|}{ Wind speed, $\mathrm{m} / \mathrm{s}$} \\
\hline Mean & 0 & 2.48 & $2.3(1.7,3.1)$ & $0.1-7.1$ \\
\hline Maximum & 0 & 9.6 & $9(7,11.5)$ & $2.7-27$ \\
\hline Mean atmospheric pressure, $\mathrm{hPa}$ & 0 & 1017 & $1017.4(1011.8,1022.8)$ & $974.4-1041.9$ \\
\hline Mean humidity, $\%$ & 0 & 77.66 & $79(69,87)$ & $38-100$ \\
\hline AirParif Atmo, Index & 0 & 3.9 & $4(3,4)$ & $2-10$ \\
\hline
\end{tabular}

Q1 indicates first quartile; Q3, third quartile. 
Table 2. Spearman Correlations Between Environmental Parameters

\begin{tabular}{|l|l|l|l|l|l|l|l|l|}
\hline & Mean & Min & Max & Max & Mean & Mean & Mean & Air \\
& Temp & Temp & Temp & Wind & Wind & Atm & Humidity & Parif \\
\hline Mean Temp & 1.00 & & & & & & & \\
\hline Min Temp & $0.93^{*}$ & 1.00 & & & & & & \\
\hline Max Temp & $0.95^{*}$ & $0.88^{*}$ & 1.00 & & & & & \\
\hline Max Wind Speed & -0.01 & 0.03 & $-0.06^{*}$ & 1.00 & & & & \\
\hline Mean Wind Speed & $-0.14^{*}$ & $-0.06^{*}$ & $-0.19^{*}$ & $0.85^{*}$ & 1.00 & & & \\
\hline Mean Atm Pressure & $-0.10^{*}$ & $-0.15^{*}$ & -0.04 & $-0.35^{*}$ & $-0.27^{*}$ & 1.00 & & \\
\hline Mean Humidity & $-0.51^{*}$ & $-0.35^{*}$ & $-0.58^{*}$ & $0.01 \dagger$ & $0.07^{*}$ & $-0.15^{*}$ & 1.00 & \\
\hline Air Parif Atmo & $0.15^{*}$ & $0.02^{\dagger}$ & $0.22^{*}$ & $-0.34^{*}$ & $-0.36^{*}$ & $0.19^{*}$ & $-0.42^{*}$ & 1.00 \\
\hline
\end{tabular}

Atm indicates atmospheric; Max, maximum; Min, minimum; Temp, temperature.

$* P<0.001$.

$\dagger P<0.05$. 
Table 3. Bivariate Analysis Between Suspected Stroke and the Suspected Triggering Factors (Negative-Binomial Log Linear Regression Model for Counting Time Series)

\begin{tabular}{|c|c|c|c|}
\hline Environmental Variable & ERR, \% (95\% CI) & $\begin{array}{l}\text { Increment to } \\
\text { Which ERR Refers }\end{array}$ & $P$ Value \\
\hline Mean temperature & $11.17(7.77$ to 14.70$)$ & $-10^{\circ} \mathrm{C}$ & $<0.001$ \\
\hline Minimum temperature & $11.67(7.88$ to 15.59$)$ & $-10^{\circ} \mathrm{C}$ & $<0.001$ \\
\hline Maximum temperature & $8.87(6.02$ to 11.80$)$ & $-10^{\circ} \mathrm{C}$ & $<0.001$ \\
\hline Temperature range & 8.64 (2.93 to 14.68$)$ & $-10^{\circ} \mathrm{C}$ & 0.002 \\
\hline Mean humidity & $4.36(2.59$ to 6.15$)$ & $+10 \%$ & $<0.001$ \\
\hline Mean atmospheric pressure & $-5.86(-25.11$ to 18.32$)$ & $+100 \mathrm{hPa}$ & 0.647 \\
\hline Mean wind speed & $9.32(-9.48$ to 32.03$)$ & $+10 \mathrm{~m} / \mathrm{s}$ & 0.354 \\
\hline Maximum wind speed & $-1.15(-8.71$ to 4.48$)$ & $+10 \mathrm{~m} / \mathrm{s}$ & 0.626 \\
\hline Air Parif Atmo & $1.44(-0.14$ to 3.06$)$ & +1 unit & 0.0745 \\
\hline Influenza epidemic & 9.03 (3.43 to 14.92$)$ & yes vs no & 0.0012 \\
\hline
\end{tabular}

CI indicates confidence interval; ERR, excess relative risk. 
Table 4. Multivariable Analysis Between Suspected Stroke and the Suspected Triggering Factors (Negative-Binomial Log Linear Regression Model for Counting Time Series)

\begin{tabular}{|c|c|c|c|}
\hline Environmental variable & ERR, \% (95\% CI) & $\begin{array}{l}\text { Increment } \\
\text { which ERR refers }\end{array}$ & $P$ Value \\
\hline Mean temperature & $8.25(-5.48$ to 23.97$)$ & $-10^{\circ} \mathrm{C}$ & 0.251 \\
\hline Minimum temperature & $5.16(-5.85$ to 17.47$)$ & $-10^{\circ} \mathrm{C}$ & 0.372 \\
\hline Maximum temperature & $-4.66(-13.42$ to 4.98$)$ & $-10^{\circ} \mathrm{C}$ & 0.331 \\
\hline Mean humidity & $3.93(1.42$ to 6.51$)$ & $+10 \%$ & $<0.002$ \\
\hline Mean atmospheric pressure & $-12.66(-31.98$ to 12.14$)$ & $+100 \mathrm{hPa}$ & 0.288 \\
\hline Mean wind speed & $40.15(-4.13$ to 104.88$)$ & $+10 \mathrm{~m} / \mathrm{s}$ & 0.081 \\
\hline Maximum wind speed & $-7.73(-17.89$ to 3.66$)$ & $+10 \mathrm{~m} / \mathrm{s}$ & 0.175 \\
\hline Air Parif Atmo & $2.86(1.01$ to 4.75$)$ & +1 unit & 0.002 \\
\hline Influenza epidemic & $0.33(-5.36$ to 6.37$)$ & yes vs no & 0.909 \\
\hline
\end{tabular}

CI indicates confidence interval; ERR, excess relative risk. 


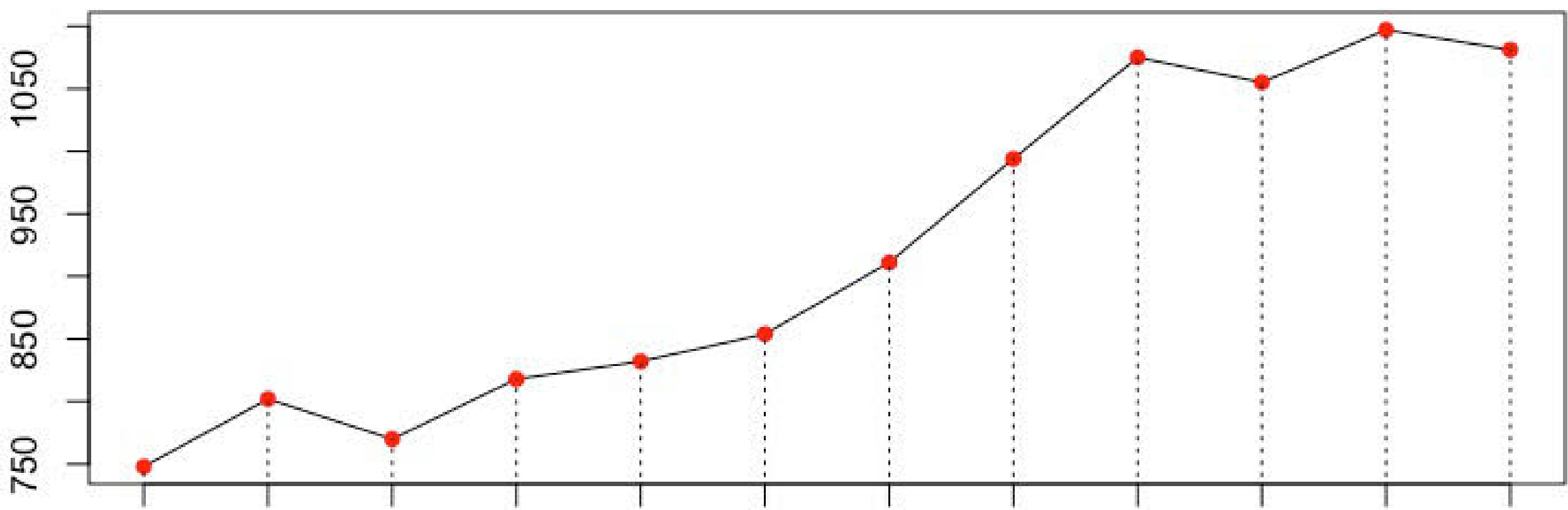

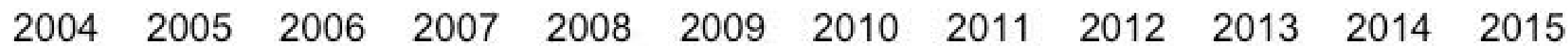

